\title{
DEVELOPMENT OF A CARTOGRAPHIC STRATEGY AND GEOSPATIAL SERVICES FOR DISASTER EARLY WARNING AND MITIGATION IN THE ECOWAS SUBREGION
}

\author{
L. A. Gueye ${ }^{\text {a }}$, M. S. Keita ${ }^{\text {b, } *}$, J. O. Akinyede ${ }^{c}$, O. Kufoniyi ${ }^{\text {d }}$, G. Erin ${ }^{\text {a }}$ \\ a ECOWAS Commission 101 Yakubu Gowon Crescent, Asokoro District, Abuja, Nigeria. (latgueye@ yahoo.com, \\ gbengaerin@yahoo.com); \\ ${ }^{\mathrm{b}}$ Regional Centre for Training in Aerospace Surveys (RECTAS), OAU Campus, Ile Ife, Osun State, Nigeria (keita@ rectas.org); \\ ${ }^{\mathrm{c}}$ Department of Remote Sensing and Geosciences Information System, Federal University of Technology, Akure, Ondo State, \\ Nigeria (jakinyede@yahoo.com); \\ ${ }^{\mathrm{d}}$ Department of Geography, Obafemi Awolowo University, Ile-Ife, Osun State, Nigeria (jidekufoniyi@ yahoo.com).
}

\author{
Commission IV, WG IV/7
}

KEY WORDS: Cartographic Strategy, Geospatial Services, Disaster, Early Warning, Mitigation

\begin{abstract}
:
The West Africa Sub-region has been crisis and disaster ridden in recent times with enormous challenges for disaster mitigation. The crisis/disasters range from conflicts fuelled by political upheaval to epidemics that take their tolls on the population of some countries in the sub-region. The crisis and disaster events have overwhelming magnitudes and are highly dynamic, requiring a well-articulated plan for immediate response in order to mitigate their effects. A study carried out by the Early Warning Directorate (EWD) of the Economic Commission of West African States (ECOWAS) highlighted the risks and vulnerabilities of the region despite the considerable progress made in development and peace consolidation in some parts of the region. The study identified apparent institutional and infrastructural deficiencies, such as the lack of up-to-date geospatial data and information, and inadequate platforms for data gathering and data sharing among the relevant national agencies, which have made much of the region particularly vulnerable to the emerging threats. It is against the foregoing that the development of a Cartographic Strategy and Geospatial Services for EWD and the ECOWAS is being proposed. In addition to the resolution of the crucial need of reliable geospatial data capacity of member states, this initiative will spearhead the realisation of a Geospatial Data Infrastructure for ECOWAS Commission, through the appropriate policy formulation and implementation. Through the proper implementation of the Cartographic Strategy and Geospatial Services, ECOWAS will have the capacity to provide geospatial analysis and mapping support focusing on areas related to conflict prevention and resolution, regional planning for food security, early warning of viral diseases and epidemics, disaster preparedness, mitigation and response, infrastructural development and refugee resettlement, and a host of other vital projects/programmes for promoting ECOWAS regional integration agenda. This paper discusses the outcome of the preliminary studies and activities carried out by an Expert Group commissioned by the EWD to develop a Cartographic Strategy and propose a framework for its implementation. These include the assessment of the status of mapping and Geographic Information System uptake in member states, the formulation of policy and the realisation of a work plan for its successful implementation in the region.
\end{abstract}

\section{INTRODUCTION}

One of the sustainable development challenges of any nation is its capacity to manage its environment and disasters. Both natural and manmade disasters can have devastating effects on people, properties and economies (Akinyede, 2005). Today, the frequency and magnitude of natural hazards and disasters threatening large populations living in diverse environments have shown a dramatic rise. The impact of disasters on the global environment has become increasingly severe over the last decades. The reported number of disasters has risen dramatically, as well as the number of people affected and the cost to global economy. About 95\% of the deaths due to disasters occur in developing countries (Kufoniyi, 2007).

West African nations have experienced many serious disaster challenges including drought, flood, coastal erosion, wild fires, epidemics, conflicts, etc. The sahelian drought of the 1980s affected West African countries and led to the loss of thousands of people, livestock and livelihoods. The increasing desertification and loss of prime agricultural lands occasioned by climate change and increased desiccation of the sudano-sahelian region led to landuse conflicts, communal and ethnic clashes and loss of lives (Adeniyi, 2009). The occurrence and severity of droughts and floods in the sub-region are happening with increasing frequency, accompanied by various diseases. Communities are more and more vulnerable to the unfamiliar hazards and cannot cope with the shocks leading to a constant rise in the number of people needing humanitarian assistance. Moreover, the number of emergencies in Africa per year has almost tripled since the mid-1980s to about 25 million people in 2005 (IFRC, 2008).

To face these challenges, efforts are being deployed in the countries through national entities which include Emergency Management Agencies, Civil Protection Agencies and Early Warning Departments. Nevertheless, despite the contributions of those agencies, tackling disaster challenges still remains a difficult task for decision makers as demonstrated by the recurrent calamities, crisis and diseases in many countries of the region in recent times. To overcome the inconsistencies, regional bodies like the Economic Community of West African States (ECOWAS) have embarked on initiatives using geospatial technology to find solutions to the problems.

The advances in geospatial technology, specifically earth observation satellite and Geographical Information System (GIS), have increased their potential to meet challenges in scientific and social fields of studies. In disaster management, 
space-based technologies and more efficient GIS tools are used to monitor the environmental changes at certain intervals and to carry out risk analysis. Indeed, geospatial technologies have contributed to providing significant solutions in all phases of disaster management areas (early warning, mitigation, preparedness, emergency response, relief and rehabilitation) in both developed and developing countries (Stevens, 2004).

However, access to relevant geospatial data needed for planning, development and management of resources has remained limited in Africa, particularly in West African countries. In addition, accurate and up-to-date base maps which provide accurate locational information as basic requirement for emergency response are not always readily available. Although national capabilities in the use of the technologies are increasing at a significant rate, yet there is a definite need to support the technology transfer, while proposing methodological approaches that are appropriate to the specific needs of the countries in the planning and decision-making on disaster management.

The current initiative of the ECOWAS Early Warning Directorate aims at assisting the ECOWAS and its Member states to improve the capabilities to manage the disaster events (pre-disaster, response and post-disaster) by using geospatial technology. The proposed Cartographic Strategy and Geospatial Services will surely provide appropriate solutions for the prevention of disaster events and emergency responses.

The main purpose of this paper is to do a systematic analysis of the geospatial capability of ECOWAS Member States in overcoming the disaster challenges affecting the region and present an overview of the Cartographic Strategy and Geospatial Services initiative of the Early Warning Directorate aimed at mainstreaming geospatial data and services. The expected results, in terms of contribution to the improvement of the ability to deal with emergencies and mitigation of major disasters, are also highlighted.

\section{DISASTER CHALLENGES IN WEST AFRICA}

The West African sub-region is comprised of 15 countries: Benin, Burkina Faso, Cabo Verde, Cote d'Ivoire, the Gambia, Ghana, Guinea, Guinea-Bissau, Liberia, Mali, Niger, Nigeria, Senegal, Sierra Leone and Togo.

Recurrent natural and human-induced disasters, such as drought, trans-boundary animal and human diseases, plant pests and diseases, as well as socio-economic and political crises have been more frequent in the sub-region of West Africa. The consequences include significantly increasing food security, child malnutrition and vulnerability of populations to shocks. The sub-region's vulnerability to disaster is already exacerbated by a number of factors, such as: poverty, low education levels and a lack of access to basic services, political instability, conflicts, poor governance, weak economic dependent on international markets, high population growth and a trend towards unplanned urbanisation and exodus from rural areas. Indeed, as of 2010, all the countries in the sub-region, with the exception of Cabo Verde, were among the countries with the lowest level of human development (FAO, 2010).
These crises in West Africa are aggravated by the impact of climate change: over the last fifty (50) years. The sub-region has undergone changes in rainfall patterns that have translated not only into serious, extensive droughts, especially in 2005, but also irregular and violent storms causing destructive floods damaging public infrastructures, homes, crops and livestock.

Such increasingly complex and diverse disasters and crises, the majority of which are transnational, require urgent commitment and intervention of regional bodies like the Economic Community of West African States (ECOWAS) taking advantage of its regional integration agenda.

\section{ECOWAS' CONTRIBUTION THROUGH EARLY WARNING IN WEST AFRICA}

\subsection{Why Early Warning Systems?}

Early warning Systems are essential in order to assess, to monitor risks and to warn of a potential crisis. In West African countries, there were local and national initiatives which often tended to prioritise the analysis of food supplies (food security) rather than other disaster challenges. This has prevented them from being able to identify vulnerabilities and formulate adequate preparation and response plans.

Since the preparedness and emergency intervention capacities and capabilities of local populations and national governments to deal with the extensive and frequent crises were weak, it became necessary to establish more efficient systems to strengthen the national capacities and coordinate the activities at regional level.

Therefore, the limited capacity of the national systems to find solutions to the crises and disaster challenges has necessitated ECOWAS Commission to initiate the establishment of a subregional peace and security observation system, pursuant to the protocol relating to the mechanism for conflict prevention, management, resolution, peace-keeping and security.

\subsection{ECOWAS Early Warning / Observation Monitoring Centre}

The ECOWAS Early Warning System (EWS) was established under Chapter IV of the 1999 Protocol Relating to the Mechanism for Conflict Prevention, Management, Resolution, Peacekeeping and Security. The Early Warning Directorate's activities include collecting open sourced information largely based on 66 pre-determined indicators of regional peace and security, analysing and submitting timely reports with recommendations to the Office of the President of ECOWAS Commission through the Office of the Commissioner, Political Affairs, Peace and Security. The EWD performs these activities through the ECOWARN Field Reporter, a web-based field monitoring, interactive analysis, and visualization tool customized for the ECOWAS region. It functions by a network of 77 field monitors, collecting early warning data and feeding it to the ECOWARN Situation Room in Abuja, the headquarters of the system. 
Recent developments in the system seeks to operationalise the National Early Warning and Response Mechanisms (NEWRMs) in Member States, a decentralized early warning and response system that involves all key stakeholders at the local, national and regional levels.

ECOWAS EARLY WARNING OBSERVATION AND MONITORING ZONES

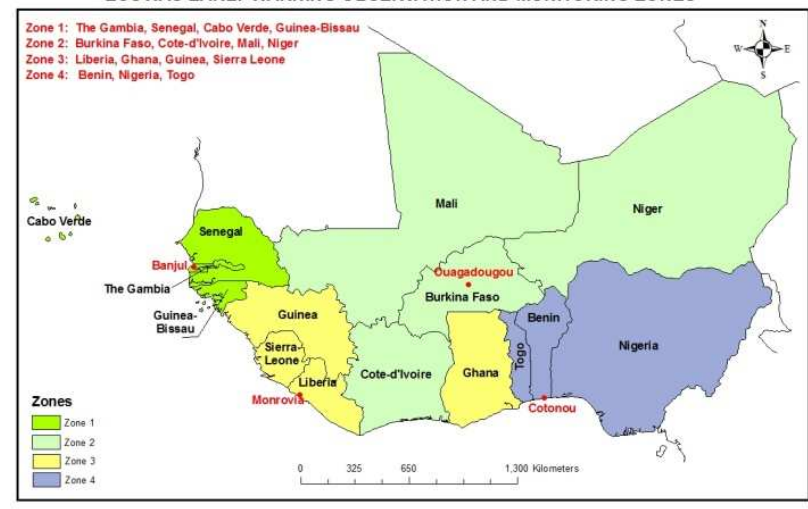

Figure 1. - ECOWAS Early Warning Observation zones by country

The Directorate works in partnership with representatives of ECOWAS Member States and Civil Society Organisations like West African Network for Peacebuilding (WANEP), West African Civil Society Forum (WACSOF) and research Institutes. It also collaborates with other Regional Economic Communities (RECs) and the African Union (AU) in the establishment of the Continental Early Warning System (CEWS).

\subsection{Best practice in risk prevention and disaster mitigation}

Experience has shown that the difference in the level of vulnerability of hazards in the developed and developing countries is not really in the number and magnitude of occurrence of hazards, but in the level of disaster management - disaster preparedness (risk reduction), mitigation, and emergency responses. This is made possible through the use of geographic data i.e. geospatial data (Adeniyi, 2009). The actual questions to respond are how prepared are we for disaster management? How much do we know about our environment? and how much data and information do we have that can help us respond to crisis situation if it occurs?

Today, geospatial technology finds responses to those questions and many other pertinent questions. It has been identified as the best applied technology for risk prevention and disaster mitigation. Geospatial technology comprises many other technologies which include Remote Sensing, Geographic Information System (GIS) and Global Positioning System (GPS). While Remote Sensing remains the most comprehensive and economically cost effective tool for obtaining synoptic geospatial data required for disaster monitoring, GIS plays a major role in the acquisition and management of related to the spatial characteristics and dimensions of disasters and hazards. For high precision information on disasters location on the Earth surface, the GPS technology provides accurate field point data required for a GIS. The adoption of Spatial Data Infrastructure (SDI) as a veritable tool in mitigating the impact of disaster has also become very obvious and widely acknowledged (Kufoniyi et al, 2013).

Many countries in West Africa sub-region are already familiar with these technologies and they have the expertise and technical know-how required for disaster management using geospatial technology. Nigeria, for example, is a member of the Disaster Monitoring Constellation (DMC), which, via collaboration, is able to provide data to and access data from other partners in the event of any disaster. (Akinyede, 2005).

One of the best solutions to explore for efficient disaster management is therefore the development of a plan of action at the EWD that would coordinate the efforts being deployed by national agencies/institutions, and organise a co-operative network making use of geospatial technology. The adoption of such best practice will greatly encourage the governments of Member States, while servicing the vulnerable communities.

\section{USE OF GEOSPATIAL TECHNOLOGY IN DISASTER MANAGEMENT IN WEST AFRICA}

\subsection{Status of mapping in West Africa}

Following the setting up of a GIS unit within the ECOWAS Early Warning Department, a meeting of the Directors General of the National Mapping Organisations of the 15 Member States was held in Dakar, Senegal in February, 2010. The goal of that meeting was to review the mapping status of the region and discuss a global cartographic strategy for ECOWAS. The meeting was attended by all the 15 directors, the representatives of development partners (French Cooperation) and other experts. The different presentations highlighted the status of mapping of each country, the availability of digital data, geodetic networks, equipment and National Mapping Strategy/Policy.

As follow-up actions, the inventory of geospatial data and policies was undertaken, using a questionnaire in the first instance and a visit to each of the member states to validate the questionnaires collected.

The criteria used in assessing the "geospatial performance" of Member States are presented in table1. 
Table 1. : Scoring sheet of geospatial performance criteria

\begin{tabular}{|c|l|c|c|c|c|c|}
\hline S/N & \multicolumn{1}{|c|}{ Criteria } & Code & \multicolumn{4}{|c|}{ Score } \\
\cline { 4 - 7 } & & $\begin{array}{c}\text { Very } \\
\text { Good }\end{array}$ & Good & Fair & Poor \\
\hline 1. & $\begin{array}{l}\text { Status of } \\
\text { National } \\
\text { Mapping }\end{array}$ & C1 & 10 & 8 & 6 & 2 \\
\hline 2. & $\begin{array}{l}\text { Number of } \\
\text { agencies } \\
\text { visited }\end{array}$ & C2 & $\begin{array}{c}8 \\
(>3)\end{array}$ & $\begin{array}{c}6 \\
(=3)\end{array}$ & $\begin{array}{c}3 \\
(=2)\end{array}$ & $\begin{array}{c}2 \\
(=1)\end{array}$ \\
\hline 3. & $\begin{array}{l}\text { Availability } \\
\text { of Geosptial } \\
\text { Data }\end{array}$ & C3 & 10 & 8 & 5 & 2 \\
\hline 4. & $\begin{array}{l}\text { Synergy } \\
\text { between } \\
\text { partners }\end{array}$ & C4 & 10 & 9 & 6 & 2 \\
\hline 5. & $\begin{array}{l}\text { Evidence of } \\
\text { SDI } \\
\text { initiative }\end{array}$ & C5 & 10 & 9 & 7 & 1 \\
\hline 6. & $\begin{array}{l}\text { Level of } \\
\text { commitment }\end{array}$ & C6 & 10 & 8 & 6 & 1 \\
\hline
\end{tabular}

The resulting "geospatial performance" of each Member State is presented in tables $2 a$.and $2 b$

Table 2a. : Geospatial performance of Member States (1)

\begin{tabular}{|c|c|c|c|c|c|c|c|c|}
\hline Criteria & \multicolumn{8}{|c|}{ Country's code } \\
\cline { 2 - 10 } & BN & BF & CV & CI & GA & GH & GU & GB \\
\hline C1 & 7 & 8 & 6 & 8 & 6 & 6 & 5 & 5 \\
\hline C2 & 8 & 8 & 2 & 4 & 4 & 5 & 6 & 4 \\
\hline C3 & 7 & 8 & 6 & 8 & 6 & 6 & 6 & 5 \\
\hline C4 & 5 & 6 & 2 & 4 & 2 & 5 & 4 & 6 \\
\hline C5 & 2 & 7 & 7 & 2 & 2 & 2 & 2 & 2 \\
\hline C6 & 6 & 8 & 7 & 6 & 6 & 6 & 6 & 6 \\
\hline P* & 35 & 45 & 30 & 32 & 26 & 30 & 29 & 28 \\
\hline
\end{tabular}

From the above findings of the investigation, the status of mapping of some of the countries has been found as very low. That demonstrated the urgent need to undertake the updating of existing maps produced in the $60 \mathrm{~s}$, still in analogue form in most cases. It was further noted that the deficiency observed in the mapping industry in the region has contributed to a large extent to the widening gap between the countries and the developed world. That has seriously influenced the successful implementation of many projects including disaster management programmes.

\subsection{Approach of establishing a Cartographic Strategy and Geospatial Services for ECOWAS}

In order to achieve its intended effect of positively affecting sustainable development, geospatial information must be readily available and easily accessible to the users who need it for various decision-making processes in economic planning and development. This informed the decision to set up a standing committee of Experts to work with the Commission to spearhead the rapid development of a Cartographic Strategy and Geospatial Services for ECOWAS.
Table 2b. : Geospatial performance of Member States (2)

\begin{tabular}{|l|c|c|c|c|c|c|c|}
\hline \multirow{2}{*}{ Criteria } & \multicolumn{7}{|c|}{ Country's code } \\
\cline { 2 - 8 } & LB & ML & NIG & NG & SN & SL & TO \\
\hline C1 & 5 & 7 & 7 & 8 & 7 & 5 & 6 \\
\hline C2 & 6 & 8 & 7 & 8 & 4 & 7 & 4 \\
\hline C3 & 5 & 7 & 7 & 8 & 7 & 5 & 6 \\
\hline C4 & 4 & 7 & 6 & 8 & 9 & 4 & 5 \\
\hline C5 & 2 & 7 & 7 & 9 & 8 & 2 & 2 \\
\hline C6 & 2 & 8 & 8 & 8 & 8 & 2 & 6 \\
\hline P* & 24 & 44 & 42 & 49 & 43 & 25 & 29 \\
\hline
\end{tabular}

Note: $* P($ Performance $)=C 1+C 2+C 3+C 4+C 5+C 6$

(confirmed by countries and validated by ECOWAS)

Where $\mathrm{BN}=$ Benin, $\mathrm{BF}=$ Burkina Faso, $\mathrm{CV}=\mathrm{Cabo}$ Verde, $\mathrm{CI}$ $=$ Cote d'Ivoire, $\mathrm{GA}=$ the Gambia, $\mathrm{GH}=$ Ghana, $\mathrm{GU}=$ Guinea, $\mathrm{GB}=$ Guinea-Bissau, $\mathrm{LB}=$ Liberia, $\mathrm{ML}=$ Mali, $\mathrm{NIG}=$ Niger, $\mathrm{NG}=$ Nigeria, $\mathrm{SN}=$ Senegal, $\mathrm{SL}=$ Sierra Leone and $\mathrm{TO}=$ Togo.

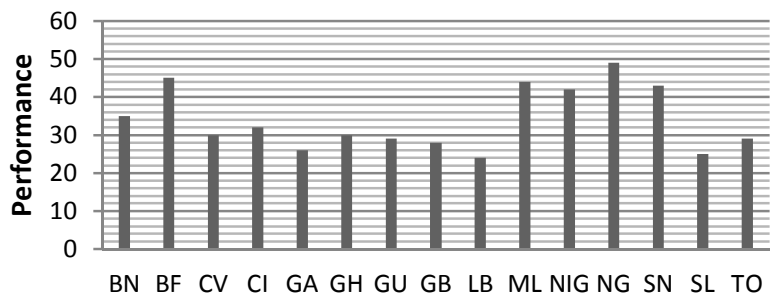

Member States

Figure 2. - Geospatial performance of ECOWAS Member States

During the first stakeholders meeting held in Dakar in February, 2010, the main activities recommended by the participants include the following:

- Identification and collection of geospatial data available in ECOWAS' member states and the Multinational Geospatial Co-production Program (MGCP) project through the French Co-operation;

- Definition and adoption of a Cartographic Strategy and Geospatial Policy for ECOWAS;

- Building and strengthening capacity and capability of Mapping agencies and other stakeholders of member States;

- Development of an ECOWAS Geospatial Data Infrastructure (EGDI).

Sequel to the meeting held in Dakar, different workshops and seminars were held in Ouagadougou (2011), Banjul (2012), Abidjan (2013) and Cotonou (2014) to discuss the development and implementation of the ECOWAS Cartographic Strategy and Geospatial Data Infrastructure initiative. A plan of action was designed and adopted, based on activities to be executed in 
collaboration with all the stakeholders, in synergy with experts and resource persons under the coordination of ECOWAS Early Warning Directorate.

\subsubsection{Geospatial data and technology availability in ECOWAS Member States}

The mission undertaken to do the inventory of geospatial data and technology available in Member States permitted to identify the data available, the data gaps and the problems of accessibility. The available data include topographic and thematic maps, geodetic networks, databases and other statistical data. The inventory also identified the types of data and the difficulties of data sharing and dissemination between stakeholders.

The inventory shows that the required geospatial technology platform including Remote Sensing technology (satellite and photography), Geographic Information Systems, Digital Cartography, ground surveying, is not fully present in all the Member States. Most countries are yet to set up a digital platform, thus the existing geospatial data are only in analogue form in many countries. The lack of internet connectivity makes in most cases the access to and dissemination of data very difficult.

However, through the Japan International Cooperation Agency (JICA) and the European Union funding, some mapping projects (large scale mapping and map revision) are currently going on in some countries (Burkina, Benin, Mali, Niger and Senegal). Furthermore, Nigeria has almost completed the analogue to digital conversion of the country's 1:50000 topographic map series and is currently undertaking the $1: 25000$ topographic mapping of the country.

\subsubsection{Cartographic Strategy and Geospatial Data Infrastructure Policy}

The need to acquire reliable and up-to-date geospatial data arose when the GIS Unit was put in place at ECOWAS Early Warning Directorate in 2010. For the production of situation reports, there was need to integrate data acquired from different sources. That brought up the necessity to harmonise the geospatial data production system in all the countries. Thus, the development of a Cartographic Strategy for the sub-region.

The Multinational Geospatial Co-production Program (MGCP) mapping project, working on the elaboration of topographic maps of West Africa at 1:50,000 scale, using satellite imageries was initiated by the French Cooperation at ECOWAS. However, the Head of National Mapping Agencies of ECOWAS Member States, during the meeting in Dakar in January 2010, strongly recommended that each country be responsible for the production of its own national maps, using at least regional standards to be developed as guidelines. It was finally decided that each country be encouraged to implement its National Spatial Data Infrastructure, while a Regional Geospatial Data Infrastructure should be developed under the coordination of EWD.
The draft policy of the ECOWAS Mapping Strategy and Geospatial Data Infrastructure was then developed in Ouagadougou in 2011, amended by Working Group of Experts and resource persons in Banjul in 2012 and validated in Abidjan in 2013. An action plan was then finalised with concrete terms of reference for working groups comprising representatives of Member States and Experts resource persons at the Expert Group meetings in Cotonou and Banjul in 2014 and 2015 respectively.

\subsubsection{Capacity building and Institutional strengthening}

The action plan will start will a full awareness building and buy-in of Ministers, Political Authorities and decision makers at ECOWAS Commission and in Member States. One of the important components of the strategy will be the increasing of the current available capacities of the region through training and capacity building programmes, institutional strengthening and funding.

The capacity building exercises will target the available human resources, who are very important for the interventions during disasters, as well as experts and resource persons who will advise on relevant equipment and infrastructure to be acquired. Other selected expert will be in charge of all institutional arrangements for putting in place conducive working environment at both national and regional levels.

\subsubsection{Development and Implementation of ECOWAS Geospatial Data Policy}

The development and maintenance of a Regional Geospatial Data Infrastructure at ECOWAS will consist of building of synergies among institutions and Member States and enabling the sharing of data and expertise for preparation of contingency plans and interventions in case of emergencies.

The proposed ECOWAS Geospatial Data Infrastructure will:

$\checkmark$ Ensure orderliness and common standard in the development and processes for executing mapping projects in the geographic space of ECOWAS.

$\checkmark \quad$ Facilitate the identification, production and sharing of fundamental datasets paramount to the regional development and integration.

$\checkmark$ Facilitate and increase the rate of mapping activities within the member states.

$\checkmark$ Provide a framework for standardizing the acquisition, processing, analysis, storage and dissemination of various geospatial datasets for socio-economic and environmental data needed to sustain and enhance regional integration and development.

$\checkmark$ Eliminate duplication in the acquisition and maintenance of geospatial datasets in the region.

$\checkmark \quad$ Encourage regional use of EGDI-endorsed standards in order to create and maintain data at a high level of quality, consistency and harmony with the ISO standards. 
$\checkmark \quad$ Promote the awareness of Geographic Information and its applications.

$\checkmark \quad$ Ensure adequate funding to maintain the EGDI vision and sustain the spirit of cooperation and collaboration amongst the member states.

$\checkmark$ Promote research, training, education and capacity building related to geospatial data production, management, dissemination and usage.

The implementation of EGDI will be done under the coordination of EWD with the contribution of Experts and resource persons. It will be done in accordance with the Plan of Action and terms of reference defining the different activities to be undertaken by the following six (6) working groups:
a. Geospatial dataset
b. Nomenclature \& Codification
c. Standards
d. Coordination, Communication \& Partnership
e. Clearinghouse \& Metadata
f. Capacity building \& Sustainability

\section{EXPECTED OUTCOMES AND BENEFITS}

For ECOWAS Geospatial Data Infrastructure to meet the stated objectives and purposes, it has to be well organised in such a way that it can provide reliable and up-to-date geospatial data and products for disaster mitigation, preparedness, emergency responses and reconstruction. It will be able to provide a Crisis Information Management System for the Early Warning Directorate, as well as relevant databases for the activities of ECOWAS Commission.

The benefits of the geospatial data and products to be generated will cover many areas of endeavour. The EGDI will be in assistance of planning and implementation of projects and programmes, as well as decision making processes in ECOWAS Commission and Member States. In the area of disaster management, conflict prevention and resolution, peace keeping and security, the following will be fulfilled:

a. Preparation of action plans for assignment of resources in response to potential crisis situations;

b. Monitoring the execution of operations, projects and programmes through the correlation and integration of information from governments, military services and other civil sources;

c. Evaluation of the potential and actual conflict situations, military force capabilities, planning for resources, use of map products, etc...;

d. Generation and updating of maps and databases that are important for disaster management, conflict prevention and peace keeping activities;

e. Preparation of reports and briefings for ECOWAS Early Warning Directorate and authorities of other departments and also for use in regional activities on disaster management.

\section{CONCLUSION}

An action plan for the establishment of a geospatial data infrastructure for ECOWAS sub-region has been presented in this paper. The infrastructure will provide effective tool for disaster mitigation, emergency response and relief. The infrastructure will provide timely and essential geospatial data and information to generate resources for preparing for and responding to various forms of disaster.

Geospatial data are often used for the preparation of contingency plans. The popular adage has it that "prevention is better than cure". While we may not necessarily be able to prevent some natural hazards, we can act to prevent their disastrous effects on vulnerable people and places. (Adeniyi, 2009). Given the heavy and enduring costs of disaster management, there is no disputing the fact that making efforts to prevent them from breaking out in the first place is better than waiting until it is too late (Souare, 2006). The earlier a disaster, a disease, a dispute or a conflict can be identified, diagnosed and its causes properly addressed, the less likely it is that the situation will deteriorate into crisis, epidemic or violence. Normally, the calamities and conflicts do not occur suddenly without warning indicators. Thus, in order to guarantee the sustainability of the prevention measures, governments and regional and international organisations must ensure that there are proper mechanisms for conflict early warning in place, based on information gathering and informal and formal fact-finding. EWD is in a position to play that role in the sub-region.

Therefore, the development of a Cartographic Strategy and Geospatial Services is not going to improve only the performance of EWD, but will be useful for the successful implementation of projects and programmes for ECOWAS Commission, as well as the execution of disaster management activities in Member States.

\section{REFERENCES}

D. Stevens (2004): Space Technology and Disaster Management- A Plan-of-action for Africa

O. Akinyede (2005): Aspects of Space Science and Technology most relevant to Africa's development: Short term and Long Term., paper presented at the $1^{\text {st }}$ African Leadership Conference on Space Science and Technology for Sustainable Development, November, 2005.

A.L. Gueye, A.O. Akingbade, O. Kufoniyi and P.B. Borisade (2004): The Use of GIS in Crisis Management: A Case Study of the Crisis Information Management System for the West African Sub-region".

Kufoniyi O., O. A. Ogundele and D. O. Baloye (2013), "Spatial Data Infrastructure (SDI): a plausible solution to improve disaster management processes in Nigeria", Journal of Sustainable Development in Africa, Vol. 15(3), 2013, Clarion University of Pennsylvania, Clarion, Pennsylvania, p130-147. 
The International Archives of the Photogrammetry, Remote Sensing and Spatial Information Sciences, Volume XL-3/W3, 2015 ISPRS Geospatial Week 2015, 28 Sep - 03 Oct 2015, La Grande Motte, France

I.K. Souare (2006): Conflict Prevention and Early Warning Mechanisms in West Africa: A Critical Assessment of Progress. - African Security Review 16.3 / Institute for Security Studies.
P.O. Adeniyi (2009): Geospatial Information and Disaster Management - Geoinformation Technology \& Development: A compendium of Selected papers. 